\title{
O REGIME MULTILATERAL DE COMÉRCIO INTERNACIONAL: CRISE E ACORDOS PREFERENCIAIS DE COMÉRCIO
}

\author{
THE MULTILATERAL REGIME OF INTERNATIONAL TRADE: CRISIS AND \\ PREFERENTIAL TRADE AGREEMENTS
}

\section{Resumo}

O objetivo deste trabalho é discutir, por meio de análise teórica e empírica, a crise do regime multilateral de comércio internacional, tendo em vista as grandes dificuldades enfrentadas pela Organização Mundial do Comércio (OMC) ao longo das últimas duas décadas. Essa crise contribui para a proliferação de Acordos Preferenciais de Comércio (APC)s em todas as regiões do mundo desde os anos 1990, processo que vem se intensificando no início deste século e tende a permanecer.

Palavres Chave: OMC; crise; Acordos Preferenciais de Comércio.

\begin{abstract}
The aim of this paper is to discuss, by means of theoretical and empirical analysis, the crisis of the multilateral regime of international trade, taking into consideration the great difficulties faced by the World Trade Organization (WTO) over the past two decades. This crisis contributes to the proliferation of Preferential Trade Agreements (PCAs) in all regions of the world since the 1990s, a process that has been intensified in the early part of this century and tends to remain.
\end{abstract}

Keywords: WTO; crisis; Preferential Trade Agreements.

\section{INTRODUÇÃO}

O objetivo deste trabalho é discutir a crise do regime multilateral de comércio internacional, tendo em vista as dificuldades enfrentadas pela Organização Mundial do Comércio (OMC) ao longo das últimas duas décadas em concluir acordos de liberalização comercial em questões sensíveis, avançar na elaboração de disciplinas comerciais, resolver disputas e equilibrar muitos e distintos interesses de seus membros.

\footnotetext{
${ }^{1}$ Graduanda em Relações Econômicas Internacionais pela Universidade Federal de Minas Gerais (UFMG), Belo Horizonte, Brasil. E-mail: beatrizfna@gmail.com

${ }^{2}$ Graduanda em Relações Econômicas Internacionais pela Universidade Federal de Minas Gerais (UFMG), Belo Horizonte, Brasil. E-mail: keniamarjory@gmail.com.

3 Professora Adjunta da Universidade Federal de Minas Gerais (UFMG), Belo Horizonte, Brasil. E-mail: patricia.nasser.carvalho@gmail.com.
} 
Desde o início da primeira e última rodada (ainda em curso) de negociações da OMC, iniciada em 2001, em Doha, ficaram evidentes as importantes conquistas e também as fragilidades da principal organização promotora e gestora das regras para a liberalização do comércio internacional de bases multilaterais.

Neste sentido, a partir de uma pesquisa explicativa, verifica-se que a crise do regime multilateral de comércio internacional, representado pela OMC, contribui para a proliferação de Acordos Preferenciais de Comércio (APC)s em todas as regiões do mundo desde os anos 1990, processo que tem se intensificado desde o início deste século.

\section{O GATT e o Regime Internacional Multilateral de Comércio}

Ao final da Segunda Guerra Mundial, Estados Unidos (EUA) e Grã-Bretanha, as duas principais potências capitalistas vencedoras do conflito, iniciaram planos conjuntos para arquitetar as diretrizes das novas instituições e dos regimes econômicos internacionais, responsáveis por estabelecer princípios e regras explícitas acordadas com outros governos (KEOHANE, 1989). Seu objetivo com os regimes internacionais era guiar o comportamento dos Estados e restaurar a ordem da economia internacional pós1945 (RUGGIE, 1982) e "admitiam que os resultados coletivos deveriam estar em harmonia com as aspirações e convicções compartilhadas pelos seus membros" (HASENCLEVER; MAYER; RITTBERGER, 2000 , p. 9). De orientação liberal, essa ordem pressupunha racionalidade do mercado e tinha natureza multilateral, ou seja, suas bases eram a cooperação entre várias nações aliadas e a coordenação das suas políticas nacionais (KEOHANE, 1990). Ao mesmo tempo, permitia a intervenção dos governos na economia, dado o seu compromisso com o "liberalismo dirigido" (RUGGIE, 1982). Desse modo, as lideranças poderiam usar de políticas domésticas para garantir o bem-estar social, realizar planos econômicos de longo prazo, estabilizar a economia e regular o mercado.

Em seu discurso, os EUA, que haviam confirmado a posição de maior potência econômica capitalista no período da Segunda Guerra, demostravam sua intenção de formar um mercado internacional único, de maneira que se fizesse possível garantir as condições para a recuperação econômica após as duas grandes guerras mundiais e a Grande Depressão dos anos 1930 a partir da promoção da liberdade econômica e do pleno emprego (DEBLOCK; HAMER, 1994). Aquele país defendia ainda a ideia de que com a restauração do mercado, a estabilidade financeira das economias e os incentivos à produção seriam retomados.

Na Conferência de Bretton Woods, realizada em 1944, foram institucionalizados o Fundo Monetário Internacional (FMI) para manter a estabilidade das taxas de câmbio das economias capitalistas e monitorar seus balanços de pagamentos e o Banco Internacional para a Reconstrução e o Desenvolvimento (BIRD) com o fim de fomentar a reconstrução dos Estados no pós-Segunda Guerra e promover seu desenvolvimento econômico. Neste arcabouço institucional, o dólar confirmou a sua posição como a principal moeda de reserva e de transações internacionais, posição garantida pelas regras do Sistema Monetário Internacional. 
Dessa forma, as regras e normas do Sistema Internacional se estruturaram na preponderância do poder político, econômico e militar dos EUA em relação às demais nações aliadas, conferindo a eles maior capacidade de impor seus interesses nas negociações internacionais. A Europa enfrentava dificuldades com a escassez de dólares e de créditos para sustentar suas necessidades (SATO, 2001). Por volta de 1946/47 novos enfrentamentos voltaram a ser uma ameaça para a região com o início da Guerra Fria. Novamente, a Europa parecia ser o palco mais provável deles. Os países periféricos, por sua vez, muito deles ainda em processo de descolonização, não tinham poder econômico ou de barganha suficiente para contestar qualquer elemento da ordem liberal que se colocava naquele momento.

De modo específico, para tratar o comércio internacional, entre novembro de 1947 e março de 1948, ocorreram em Havana reuniões preparatórias para a criação da Organização Internacional do Comércio (OIC). Na última delas, foi apresentada a chamada Carta de Havana, formalizada com 79 artigos, a qual propunha redução de tarifas sobre a importação de bens, eliminação de quotas de importação e de preferências comerciais, além da criação de disciplinas para o uso de outros instrumentos. Segundo a Carta, a OIC também teria que lidar com questões diversas como direitos trabalhistas, barreiras nãotarifárias, subsídios e acordos comerciais preferenciais (VANGRASSTEK, 2013). Os objetivos da Carta eram amplos e iam além dos interesses comerciais imediatos de determinados grupos de interesses norteamericanos relativos à liberalização do mercado mundial às suas exportações de bens (MESOUITA, 2013). $\mathrm{Na}$ fase seguinte, os Estados signatários deveriam ratificá-la, segundo os procedimentos constitucionais previstos em cada ordem jurídica.

Durante a terceira reunião do comitê preparatório da OIC em Genebra, em 1947, o texto do GATT foi elaborado com a participação de 23 nações. Com a finalidade de ser provisório durante o período de ratificação da OIC por todas as Partes, o GATT foi aprovado para ser um fórum de negociações para a liberalização comercial. A elaboração de normas seria de prerrogativa das Partes Contratantes e não da secretaria de uma organização, como no caso da OIC (WOOLCOCK, 2012). Ele continha, em princípio, o compromisso dos governos para reduzir tarifas e um código de conduta regulando outras formas de política comercial (HUDEC, 1987).

As Partes Contratantes do GATT se comprometeram em seguir a cláusula da Nação Mais Favorecida (NMF), estabelecida no Artigo I, e a cláusula do Tratamento Nacional, enunciada no Artigo III. Cerne do acordo, o Artigo I, que determinava que qualquer benefício concedido a um Estado signatário deveria se estender aos demais, obrigando as Partes a não discriminarem produtos originários de diferentes países, ao passo que o Artigo III indicava que os produtos importados, ao se inserirem em solo nacional, deveriam receber o mesmo tratamento que as mercadorias domésticas, independentemente da sua origem. Outros princípios, como transparência e consolidação dos compromissos das Partes, também foram agregados ao GATT. Além desses, mais de três dezenas de artigos definiram as bases para a liberalização do comércio no tocante aos direitos e aos compromissos das Partes.

Os governos não ficaram proibidos de proteger indústrias domésticas da competição estrangeira, embora todo tipo de proteção deveria dar-se na forma de tarifas. Enquanto não houvesse a priori limites 
para os níveis tarifários, os governos participariam das negociações periódicas para gradualmente os reduzirem (GILPIN, 2001). Por meio desse princípio, eles aceitaram eliminar diversos outros tipos de medidas não-tarifárias, as quais haviam se tornado comuns no período entreguerras, especialmente as restrições que limitavam a quantidade de importações.

Na prática, desde 1947, quando foi aprovado, o GATT representou a consolidação das negociações comerciais e, ao mesmo tempo, a eliminação de barreiras tarifárias promovidas pelos acordos bilaterais norte-americanos já realizados até aquele momento (MESOUITA, 2013). Porém, a falta de consenso sobre mecanismos para comprometer as Partes, de um órgão de solução de controvérsias e de instrumentos de sanção capazes de induzir com eficácia a ação dos governos, especialmente dos mais poderosos (SATO, 2001) - sobretudo dos EUA -, bloqueou a criação de uma organização de facto no pós-Segunda Guerra. Após mais de dois anos de tentativas do governo norte-americano de aprovar a Carta de Havana no Congresso do seu país, depois de várias negativas, em 1950, o projeto da OIC foi inviabilizado. Em face desse acontecimento, o GATT não se transformou em uma organização internacional multilateral com termos mais específicos para orientar as trocas comerciais nas quatro décadas seguintes à sua aprovação. No entanto, os EUA entenderam que o regime de comércio internacional representado pelo GATT deveria ajudá-los a coordenar o comportamento dos demais Estados de forma que pudessem alcançar resultados considerados ótimos no comércio internacional (HASENCLEVER; MAYER; RITTBERGER, 2000).

\section{As Rodadas de Negociações do GATT: Alcances e Limites}

Uma vez que diversos temas da agenda de negociações haviam sido contemplados pela OIC, mas não pelo GATT-1947, como o acordo ficou conhecido, ele ficou sem autoridade legal para lidar com a liberalização comercial de bens agrícolas, serviços, direitos de propriedade intelectual e de investimentos ligados ao comércio (GILPIN, 2001), concentrando-se, assim, nas negociações de liberalização comercial de produtos manufaturados.

A exclusão de várias barreiras não-tarifárias das negociações do GATT reforçou ainda a concepção de que o processo de liberalização se restringia à disciplina tarifária (JACKSON, 1997). Embora coerente, as regras de política comercial colocadas pelos artigos do GATT eram bastante modestas, ou seja, estavam muito longe de ter condições para garantir o livre comércio internacional.

A natureza limitada do GATT foi reforçada pelas ressalvas e válvulas de escape ao Artigo I. Ainda que, em princípio, não fosse simples contorná-lo, pois isso dependia de justificativas e de considerável poder de barganha de cada país, as exceções estiveram presentes desde o início da aprovação do GATT, na Parte Il do acordo. Em teoria, elas refletiam as medidas domésticas em casos considerados excepcionais em relação ao processo de liberalização (RUGGIE, 1982). Ao mesmo tempo em que contradiziam o princípio mais caro do GATT, na prática, abriam espaço de manobra para cada Parte decidir como desejaria liberalizar seu mercado (WOOLCOCK, 2012). Portanto, para além da reciprocidade, a flexibilidade foi uma 
característica do GATT e seu uso ficou condicionado ao poder da Parte solicitante e à conveniência da interpretação dos princípios pelos demais interessados.

As exceções ao Artigo l iam desde a imposição temporária de restrições quantitativas à importação por uma economia em razão da queda de reservas internacionais do seu Balanço de Pagamentos até a utilização de mecanismos de assistência governamental para promover o desenvolvimento econômico por meio da proteção da indústria infante. Esse último item interessava particularmente aos países europeus no pós-Segunda Guerra, uma vez que não se sentiam preparados para abrir seus mercados e desejavam manter seus regimes tarifários preferenciais (HUDEC, 1987). Ademais, entre as décadas de 1950 e 1960, muitos países do Terceiro Mundo lançavam seus programas de substituição de importações a fim de desenvolver sua indústria e, por isso, também tinham interesse em proteger seu mercado doméstico.

No caso específico do comércio preferencial, o Artigo XXIV autorizava a criação de APCs, desde que atendessem a determinadas condições, com a pretensão de estimular esquemas de comércio regionais que promovessem reciprocidade e, em última instância, o multilateralismo no comércio internacional (PANAGARIYA, 1999). Por considerarem a agricultura um setor especial, tanto europeus quanto norte-americanos, se posicionaram contra a inserção desse tema nas negociações de liberalização comercial. Acima de tudo, as regras do GATT tinham de ser compatíveis com as suas políticas agrícolas nacionais protecionistas.

As exceções e sua natureza não obrigatória demonstravam que a liberalização do comércio internacional no GATT poderia ser seletiva e o multilateralismo limitado. A ordem econômica do pósSegunda Guerra, assim como em outras instâncias e regimes internacionais multilaterais recéminstitucionalizados, estava atrelada à vontade política de seus membros, uma vez que as decisões nessas instâncias afetavam suas políticas domésticas. Ao mesmo tempo, face ao enorme diferencial de poder dos EUA em relação às demais nações, eles tinham mais condições de arbitrar em questões comerciais gerais (SATO, 2001). Além de deterem o maior parque industrial do mundo, em plena atividade, precisavam de mercados de consumo externos (SATO, 2012), tendo em vista que produziam diversos bens em excesso.

Inicialmente não houve nos artigos do GATT disposições referentes ao desenvolvimento econômico, tampouco existiam regras, compensações ou exceções especiais para os Países em Desenvolvimento (PEDs) e Países Menos Desenvolvidos (PMDs), os quais compunham o Terceiro Mundo (HUDEC, 1987). Por conseguinte, a despeito de que muitos deles adotassem políticas de industrialização por substituição de importações, seus bens tinham que competir no mercado internacional com os dos demais países do Centro.

Apesar de suas limitações, o longo das décadas seguintes, o GATT se consolidou não somente como um fórum de grande importância para a promoção do regime de comércio internacional (GILPIN, 2001), mas como uma organização internacional de facto (MESOUITA, 2013). Nas cinco primeiras rodadas do GATT, as reduções tarifárias alcançaram quase metade de todas as trocas daquele tipo de bem ${ }^{4}$

4 Após a assinatura do GATT, em Genebra, em 1947, as demais rodadas multilaterais de negociações foram: Annecy (1949), Torquay (1951), Genebra (1956) e Dillon (1960-61). 
(O'BRIAN e WILLIAMS, 2004) e o comércio internacional cresceu a taxas médias de $8 \%$ ao ano de 1948 a 1960 (MESOUITA, 2013). Milhares de concessões tarifárias foram realizadas. Os fluxos econômicos, de maneira geral, cresceram rapidamente, tendo em vista que a economias aliadas capitalistas vinham se recuperando. Consequentemente, os mercados capitalistas se integravam cada vez mais (GILPIN, 2001).

Nesse âmbito, tanto os EUA, quanto as economias europeias ocidentais e o Japão se mostravam satisfeitos com os resultados da ordem econômica liberal sob a liderança dos EUA (HUDEC, 1987). Até a Rodada Uruguai, a última do GATT, findada em 1994, os focos de insatisfação se restringiram, basicamente, aos países periféricos, que não encontravam respostas suficientemente satisfatórias para as suas demandas e continuavam sendo minoria entre as Partes Contratantes do GATT. Como o sistema de votos era por consenso, quando acontecia, eles tinham pouco peso político (HUDEC, 1987).

Diante da grande pressão exercida sobre os Países Desenvolvidos (PDs), quando as diretrizes da Rodada Kennedy (1964-67) foram delineadas, as Partes Contratantes tomaram medidas para contemplar as demandas dos PEDs e PMDs, as quais resultaram na Parte IV do GATT, aprovada em 1965. Seu principal objetivo era eliminar os resultados desiguais da aplicação da cláusula NMF e permitir a proteção das indústrias nascentes nos PEDs e PMDs (WILLIAMS, 1987). Teoricamente, abria-se um novo capítulo sobre comércio e desenvolvimento, visto que houve concordância no GATT em conceder tratamento especial às exportações daqueles países (GILPIN, 2001), embora, na prática, grande parte das suas exportações continuasse sofrendo tratamento discriminatório.

Mais adiante, em 1979, a Cláusula de Habilitação do GATT também permitiu a formação de APCs em duas circunstâncias: na primeira, os PDs foram autorizados a conceder preferências parciais unilaterais para bens provenientes dos mercados de PEDs e PMDs (por meio da isenção do Artigo l); na segunda, dois ou mais PEDs ou PMDs ganharam o direito de trocar preferências comerciais parciais entre si, sem a necessidade de estendê-las aos PDs para facilitar e promover comércio sem criar barreiras indevidas. Efetivamente, porém, essas medidas compensatórias tiveram poucos efeitos em razão da falta de competitividade da indústria e das dificuldades econômicas enfrentadas pelo Terceiro Mundo.

Entre os vários acordos alcançados nas negociações, os códigos da Rodada Kennedy (1961-64) sobre regras antidumping e de valoração aduaneira, e os acordos da Rodada de Tóquio (1973-79) sobre Compras governamentais, barreiras técnicas, subsídios e medidas compensatórias (VANGRASSTEK, 2013) se destacaram. Essas foram as primeiras tentativas de alcançar acordos sobre barreiras não-tarifárias no GATT, embora elas somente se aplicassem às Partes que os subscrevessem. Os PEDs e PMDs, em sua grande maioria, não se dispunham a aprovar esses códigos.

Assim, durante o processo de barganha no GATT, ficaram perceptíveis as dificuldades das Partes de negociarem itens não relacionados às tarifas em razão da sua natureza política (SATO, 2001), ao passo que eram aceitas resoluções sobre cortes tarifários significativos para a maioria de produtos industrializados. Consequentemente, nos anos 1970, ficou perceptível a frustração por parte dos EUA e da 
Comunidade Econômica Europeia (CEE) ${ }^{5}$ com relação à abordagem GATT à "la carte" dos PEDs e PMDs. Na mesma década a economia internacional foi abalada por uma forte crise internacional com epicentro nos EUA, estimulando práticas protecionistas, as quais voltaram a dar o tom do comércio internacional: as barreiras não- tarifárias se proliferaram, além de práticas consideradas injustas.

Desde o final dos anos 1960, as regras da ordem econômica internacional, aceitas em Bretton Woods, não encontravam mais as mesmas condições de outrora: o dólar sofria ataques especulativos, os EUA acumulavam déficits comerciais consecutivos, sobretudo com alguns países da CEE e com o Japão e, por isso, perdiam reservas internacionais, o que provocava déficits em suas contas externas e pressões inflacionárias. Esse quadro foi agravado com os choques do Petróleo (1973 e 1979) e com as tensões geopolíticas provocadas pela Guerra Fria.

A resposta norte-americana a esses desequilíbrios foi a adoção de ações unilaterais a partir de 1971, abandonando a conversibilidade da taxa de câmbio fixa ouro-dólar e instaurando o câmbio flexível. No final daquela década, os norte-americanos pressionaram europeus e japoneses a valorizarem suas moedas frente ao dólar, impuseram um rigoroso controle interno sobre os preços e salários para conter a inflação e aumentarem a sua taxa de juros a fim de atrair capitais, além de que reaqueceram os gastos da sua indústria armamentista (GILPIN, 2001).

Na década seguinte, as controvérsias acerca da inclusão de novas questões da agenda de negociações, até então combatidas pelos PEDs e pelos PMDs, geraram o maior nível de tensões até então experimentado no GATT, exacerbadas pela natureza não compulsória dos mecanismos de resolução de conflitos, pela incapacidade do Acordo de sancionar membros por desvios de conduta, pelas várias exceções às regras e interpretações convenientes. De fato, o GATT não conseguia resolver os desequilíbrios gerados pelo próprio regime multilateral de comércio internacional.

Na última rodada de negociações do GATT, a Rodada Uruguai, originalmente planejada para durar quatro anos, as negociações foram iniciadas em setembro de 1986 e formalmente encerradas em abril de 1994 na Conferência Ministerial de Marraqueche. Na ocasião, os EUA se empenharam com afinco em expandir a agenda do GATT para outras questões que afetavam o comércio e que lhe interessavam mais. Assim, a contragosto dos PEDs e PMDs, foram aprovados dois acordos para padronização de comércio de serviços e de investimentos, respectivamente (THORSTENSEN, 2012) e mais um para garantir a proteção da propriedade intelectual (PI).

Na conclusão da Rodada Uruguai foram também sancionados acordos para disciplinar as barreiras não-tarifárias, como medidas sanitárias e fitossanitárias, salvaguardas, regras para o comércio de produtos têxteis, subsídios às exportação agrícola e medidas compensatórias (WOOLCOCK, 2012). Esses "novos temas" foram agregados à agenda da Rodada Uruguai, mesmo sendo objeto de muitas controvérsias, uma vez que relacionavam o comércio às políticas governamentais.

${ }_{5}$ A CEE foi institucionalizada pelo Tratado de Roma de 1957. Seus membros fundadores foram: Alemanha Ocidental, França, Itália, Países Baixos, Luxemburgo e Bélgica. 
A despeito de suas limitações, fosse pelos alcances da liberalização dos fluxos internacionais de comércio desde o final dos anos 1940 no âmbito multilateral, pelo número países que se tornaram membros - inicialmente eram 23, na Rodada de Genebra, em 1947; em 1986, na Rodada Uruguai, participaram 123 países (O'BRIAN; WILLIAMS, 2004) - ou pela sua capacidade de agregar temas à agenda de negociações, aprovar regulações de política comercial e eliminar tarifas, o GATT foi um fórum de grande importância para a promoção do regime de comércio internacional até o início dos anos 1990 (MESOUITA, 2013).

\section{A OMC e a crise do Regime Multilateral de Comércio Internacional}

No início dos anos 1990, na esteira do processo de globalização econômica internacional, da maior abertura unilateral dos mercados aos fluxos de capital financeiro e de investimentos, de bens e de serviços e diante da estratégia de inserção internacional de muitos países no mercado internacional, o final da Guerra Fria mudou definitivamente os contornos do Sistema Internacional. Com a fragmentação da União Soviética e a queda do Muro de Berlim, os EUA conseguiram se afirmar como a única grande potência no mundo. Além disso, não havia mais razões geopolíticas para que o comércio fosse tratado como uma questão de segurança, como havia acontecido anteriormente. Por isso, insistir em barganhar os "novos temas" foi tão importante naquele momento para os norte-americanos. Neste contexto, as políticas nacionais se encontravam crescentemente influenciadas pelo aumento da importância de empresas transnacionais, tratando comércio e investimentos como atividades complementares; tornava-se mais difícil criar e implementar regras sobre troca de bens que envolviam origens nacionais distintas (THORSTENSEN, 1998).

O final da Rodada Uruguai foi marcado por um novo momento das relações multilaterais de comércio internacional a partir da institucionalização da OMC com a assinatura do Tratado de Marraqueche por 76 governos em 1994. Ele reforçava que o comércio deveria ser regido por regras multilaterais e não preferenciais (GILPIN, 2001) e promulgava a OMC como a administradora máxima do conjunto fundamental de regras do comércio internacional. Além de incorporar os princípios do GATT chamado GATT-1994 e que tratava apenas de comércio de bens - e todos os demais acordos aprovados na Rodada Uruguai, a OMC ganhou status de organização econômica internacional com personalidade jurídica, em 1995, munida de um Órgão de Solução de Controvérsias (OSC), de um secretariado e de outras estruturas administrativas.

Seu objetivo maior era desenvolver o regime multilateral de comércio internacional integrado e durável (MESOUITA, 2013) em um contexto geopolítico internacional completamente diferente do conflito bipolar. Além de construir um espaço multilateral por excelência para celebração de acordos e normas relativas ao comércio internacional, a OMC ganhou posição fiscalizadora do regime multilateral de comércio internacional e criou um espaço importante para solução de conflitos entre seus membros, devendo administrar os procedimentos relativos a eles (THORSTENSEN, 1998). Em suma, sua autoridade 
política foi fortalecida vis-à-vis ao GATT e a cobertura setorial expandida, colocando em vigor os acordos fechados em Marraqueche.

O processo de consolidação de aparatos jurídicos, administrativos e técnicos durante a primeira bateria de negociações comerciais sob o comando da OMC no âmbito da Rodada Doha, também chamada de Rodada de Desenvolvimento do Milênio da ONU, lançada em 2001, na capital do Catar, colocou ambiciosos desafios à mesa de negociações: de redução das barreiras comerciais dos produtos industriais, especialmente sobre bens provenientes dos PEDs e dos PMDs, incluindo serviços ao aperfeiçoamento do acordo de investimentos e políticas de competição, revisão da política antidumping e das regras de PI (THORSTENSEN, 1998). A agenda de negociações da OMC tratou ainda de assuntos cada vez mais complexos, como padrões justos de trabalho e proteção do meio ambiente, soberania nacional e outras questões que não eram suscetíveis a barganhas fáceis ou a soluções compromissadas. Ou seja, além de extensa, a agenda da OMC envolvia assuntos bastante complicados.

Por conseguinte, as negociações da Rodada, que deveriam ser finalizadas antes de $1^{\circ}$ de janeiro de 2005, evidenciaram as importantes conquistas da OMC e também suas fragilidades como a principal organização promotora e gestora das regras para a liberalização do comércio internacional de bases multilaterais. Sem dúvida, os fluxos de comércio internacional foram consideravelmente liberalizados nas últimas décadas e isso se deveu, em grande medida, às disciplinas e aos acordos da OMC. As barreiras tarifárias e não-tarifárias foram reduzidas em níveis maiores do que no período pré-OMC. A grande maioria das linhas tarifárias dos PDs caíram e houve progressos substanciais na redução das tarifas de bens e serviços de PEDs e PMDs. O crescimento médio anual das taxas de exportação de bens subiu de 5,6\% entre 1981-94 para 8,9\% entre 1995-2010 (BHAGWATI; KRISHNA; PANAGARIYA, 2014).

Contudo, até hoje inconclusa, a Rodada Doha resiste às dificuldades relativas ao término de acordos em questões sensíveis, ao avanço da elaboração de disciplinas comerciais, à resolução de disputas e ao equilíbrio de muitos e distintos interesses de seus membros. A euforia de pouco mais de uma década de realizações do multilateralismo no domínio da OMC, mesmo agregando partes que juntas realizam 95\% do comércio mundial, parece em crise. Com ela, o multilateralismo, como princípio básico da política internacional, ao menos como pensado no pós-Segunda Guerra Mundial também encontra-se em crise. Em particular, EUA, União Europeia $(U E)^{6}$ e Japão se convenceram dos custos políticos de baixar certas barreiras ao comércio.

São vários os obstáculos ao avanço da Rodada Doha. Um deles se deve à necessidade de consenso entre um grande número de membros da OMC. Quando foi aprovado, em 1947, eram 23 partes contratantes do GATT - entre as quais, o Brasil. Na atualidade, são 164 membros (WTO, s.d.) $)^{7}$, o que implica em diversos interesses, muitas vezes contraditórios. Cada um deles tem a sua política comercial que pode alterar a distribuição de recursos dentro do país, gerando resistências à perda de autonomia que

\footnotetext{
${ }^{6}$ A UE foi criada pelo Tratado de Maastricht de 1992 e, além da CEE, incorporou outros pilares relativos à integração regional da Europa.

7 WTO - World Trade Organization. Disponível em: https://www.wto.org/english/thewto_e/whatis_e/tif_e/org6_e.htm. Número de fevereiro de 2018.
} 
decorreria de acordos comerciais multilaterais. Persiste, dessa forma, em muitos membros da OMC, a ideia de que o mercado doméstico é patrimônio dos produtores nacionais? (MESOUITA, 2013).

Além dos acordos existentes sobre temas sensiveis e trabalhosos de negociar gerarem descontentamentos, há ainda guerras cambiais e debates inconclusos sobre padrões justos de trabalho, direitos humanos e consequências dos movimentos transfronteiriços - não apenas de bens, mas de serviços, capital, de pessoas, informações e até mesmo de ideias - porque são contestáveis e dependem do ponto de vista de cada membro da OMC. Assim, por serem complexas, as discussões sobre códigos e normas se arrastam por anos (VANGRASSTEK, 2013).

Por outro lado, o protecionismo recentemente toma novas feições. A proliferação das barreiras não-tarifárias e seu emprego como modo dissimulado de protecionismo ampliam os riscos decorrentes da imposição unilateral de padrões técnicos ao comércio internacional (PRAZERES, 2002). Assim, são demandados acordos ou códigos gerais, que, ao mesmo tempo são cada vez menos prováveis de serem aceitos por todos os membros da OMC.

O sistema de tomada de decisão dentro da OMC também não favorece o progresso das negociações. O single undertaking, adotado na Rodada Uruguai por demanda dos PDs, foi agregado ao consenso, que já fazia parte do texto do GATT como elemento primordial do processo decisório do acordo. Enquanto o primeiro afirmava que todas as questões devem ser negociadas simultaneamente e "nada é concordado até que tudo fosse concordado", o segundo concedia poder de veto à parte reclamada em qualquer etapa do processo, da formação do painel à aprovação do relatório (MESOUITA, 2013). Com a adoção do single undertaking, os PDs estavam determinados a assegurar que os PEDs tivessem apenas tratamento especial restrito a períodos mais longos de transição para adoção de regras (WOOLCOCK, 2012), evitando, assim o GATT à "la carte". A adoção do single undertaking passou a dificultar o processo de tomada de decisão e a conclusão de acordos na OMC (THORSTENSEN, 2012).

A falta de vontade política, sobretudo por parte dos PDs, de concluir mais uma etapa do processo de liberalização e as novas regras do comércio internacional (THORSTENSEN, 2012) são fatos que vêm minando os resultados das negociações na OMC. Mesmo que o OSC possa ser considerado um mecanismo ativo, os EUA e a UE demonstram que gradativamente têm reduzido as suas expectativas quanto a resultados dos acordos na OMC da forma conveniente. A crise internacional de 2007/2008 e suas consequências implicaram ainda na queda das suas taxas de crescimento econômico e na revisão de suas políticas, inclusive comerciais, a fim de ganhar competitividade e ampliar sua participação no mercado internacional.

A indiscutível e crescente resistência por parte dos PEDs e PMDs às decisões do Quad - formado por EUA, UE, Japão e Canadá - da OMC e o aumento do seu poder de barganha nas últimas décadas são elementos indiscutíveis para a caracterização da crise do regime multilateral de comércio internacional, representado pela OMC. Muitos deles, só ingressaram recentemente na organização, embora tão logo formassem resistências vitais para dificultar o avanço das negociações quando as maiores potências insistem em acordos desequilibrados. Até agora, diversas coalizações formadas por PEDs e PMDs se 
mostram firmes na posição de não aceitarem a inclusão de novos temas à agenda da OMC sem contrapartidas viáveis (BHAGWATI; KRISHNA e PANAGARIYA, 2014). Eles também não se contentam em realizar concessões não recíprocas temporárias, as quais, na verdade, não compensam décadas de desequilíbrios no comércio internacional.

As diferenças de interesses entre PD e PEDs de economias emergentes foram motivos suficientes para que a Rodada Doha chegasse a ser paralisada em diversos momentos, culminando com o seu colapso na Reunião Ministerial de Genebra, em 2008. Em particular, as divergências sobre o mecanismo de salvaguardas agrícolas destinadas a proteger agricultores dos PEDs foram o gatilho. Neste século, os PEDs e PMDs têm maior representatividade no regime de comércio internacional e constituem players muito mais influentes se comparado ao período em que a OMC foi criada. No entanto, mesmo que esses países tenham alcançado importantes vitórias, como na Reunião Ministerial de Bali, em 2013, com a aprovação do Acordo de Facilitação de Comércio e regras para a eliminação de todas as formas de subsídio às exportações agrícolas eles ainda não ficaram satisfeitos com os alcances (BHAGWATI; KRISHNA; PANAGARIYA, 2014).

Neste contexto, a despeito da sua importância, a OMC deixa um vácuo que vem sendo preenchido por outras instâncias de negociação do comércio internacional. Os APCs, cujo processo de proliferação se deu a partir dos anos 1990, embora não se sobreponham à OMC como o principal locus das negociações de liberalização e de regulação do comércio internacional, certamente ocupam no início do século XXI um espaço crescente diante da crise do regime multilateral de comércio internacional. Em busca de proteger seus interesses, expandir o comércio e agilizar negociações, tanto PDs quanto PEDs e PMDs crescentemente orientam suas políticas comerciais em direção aos APCs, que serão estudados na sequência.

4. Proliferação Mundial de APCs: configurações

APCs são definidos, de maneira ampla, como todos aqueles acordos recíprocos, realizados entre grupos específicos e com caráter preferencial. Estes, por sua vez, são classificados em Áreas de Livre Comércio (ALC)s; Uniões Aduaneiras (UA)s; Acordos de Integração Econômica (AIE) e Acordos de Alcance Parcial.

A crise do regime multilateral de comércio internacional gerou impactos diretos no número de APCs firmados mundialmente. Como indicado na Figura 1, após o início da Rodada Doha, em 2001, houve crescimento expressivo desses acordos, reafirmando seu posicionamento emergente a partir da década de 1990.

Figura 1 - Evolução dos Acordos Preferencias de Comércio, 1948-2017 
45
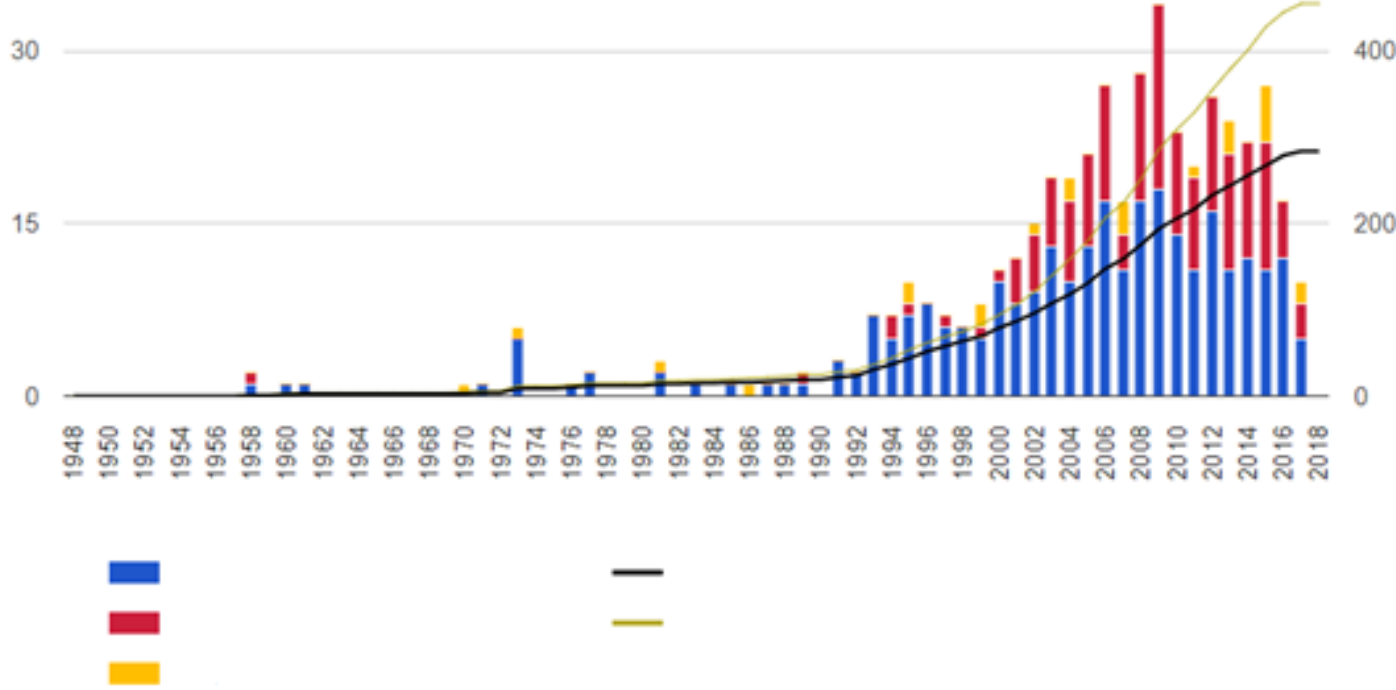

Fonte: WTO

Segundo a OMC, conforme dados sintetizados na Tabela 1, atualmente existem 455 APCs em vigor e notificados à organização sob os artigos ou cláusulas que os regulamentam. Destes, 235 são ALC e 20 UA, as quais seguem o Artigo XXIV do GATT 1994. Os APCs firmados por PEDs, conforme previsto pela Cláusula de Habilitação, somam 49 acordos, ao passo que aqueles formulados para liberalizar o comércio de serviços, como enunciado no Artigo V do GATS, adicionam 151 acordos.

Tabela 1 - APCs em vigor no mundo (por tipo de notificação)

\begin{tabular}{cccc} 
& Acessos & Novos APCs & TOTAL \\
\hline Artigo XXIV do GATT (ALC) & 3 & 232 & 235 \\
Artigo XXIV do GATT (UA) & 10 & 10 & 20 \\
Cláusula de Habilitação & 5 & 44 & 49 \\
Artigo V do GATS & 7 & 144 & 151 \\
TOTAL & 25 & 430 & 455 \\
\hline
\end{tabular}

Fonte: WTO (dados até dezembro de 2017)

Para além desses 455 acordos supraditos, um volume significativo de APCs não foram aqui computados, visto que fazem menção àqueles acordos ainda não notificados à OMC, o que só confirma a sua pandemia nos últimos anos.

Somente na última década, constata-se uma média de 23 notificações por ano, em oposição à média de menos de 1 notificação anual durante os 47 anos de GATT (1948-1995). A proliferação de APCs tem se difundido por todas as regiões do globo, o que pode ser observado na Figura 2. Dos 455 APCs, 151 correspondem ao Leste Asiático, sendo a região com maior concentração de acordos em vigor e notificados a OMC. Já a Europa dispõe de 117 acordos, o que condiz com pouco mais de um quarto do total. A América do Sul, por sua vez, ocupa a terceira posição, contando com uma parcela de $21 \%$ dos APCs registrados até dezembro de 2017. 
Figura 2 - Número de APCs por região

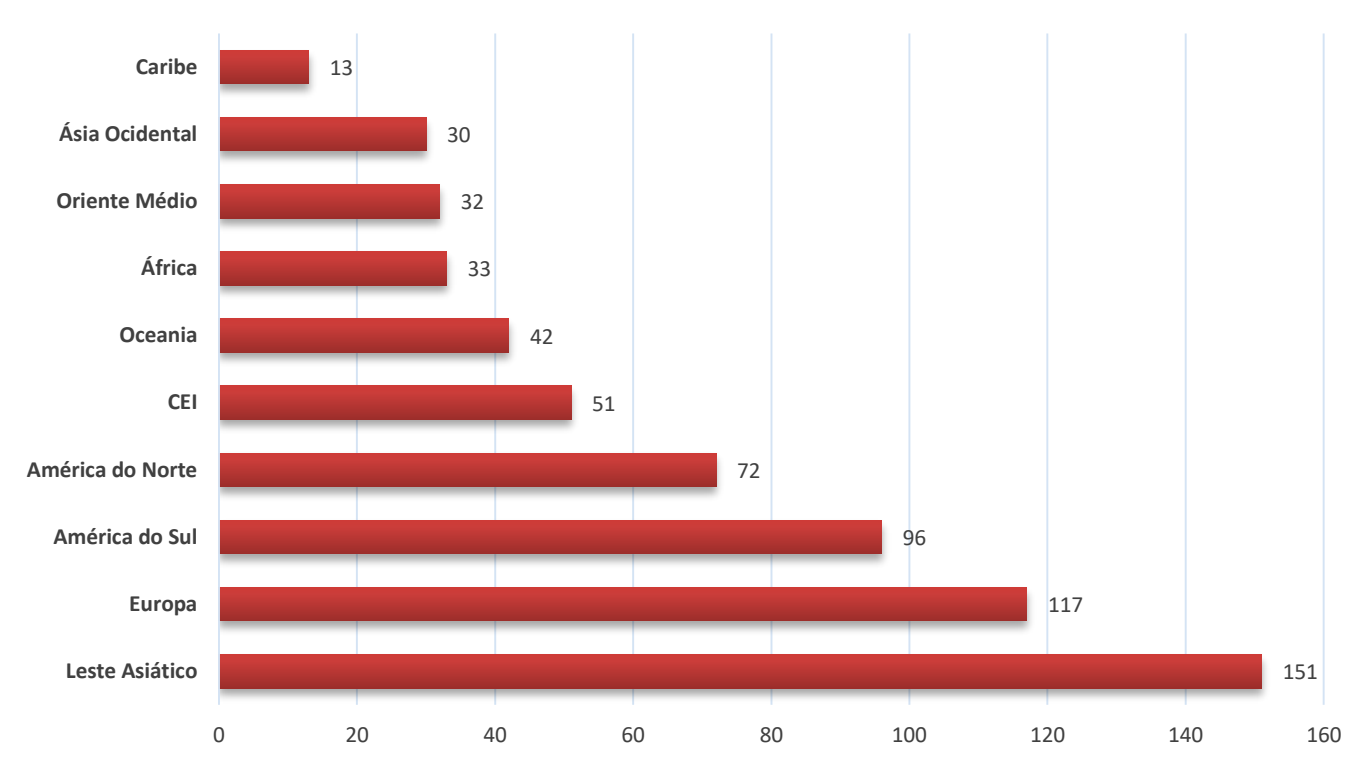

Fonte: Elaboração própria a partir de dados da WTO.

APCs podem ser classificados, a partir da composição de seus membros, como bilaterais, plurilaterais e inter-regionais. Os bilaterais são normalmente aqueles constituídos por duas partes. Entretanto, podem incluir mais de dois países quando uma das partes corresponder a um APC (BACCINI; DÜR; ELSIG, 2014) ${ }^{8}$. Já os plurilaterais referem-se àqueles acordos em que o número de partes constituintes excede dois países (ACHARYA et al., 2011), mas que não se enquadram na categoria interregional ${ }^{9}$. Por fim, os acordos inter-regionais são os assinados entre duas entidades regionais ${ }^{10}$.

Desde os anos 1990, é notória a predominância de acordos classificados como bilaterais ou plurilaterais. No Leste Asiático, Cingapura recebe destaque ao participar de 42 APCs, seguida por Coreia do Sul e Japão. Ainda que o avanço dessa estratégia comercial por parte da China seja evidente nos últimos anos, o país ocupa a quarta colocação em sua região, contando com 27 APCs em vigor.

Na Europa, a União Europeia tem maior notoriedade. O bloco possui uma política comercial comum e, consequentemente, seus Estados-Membros não podem fazer acordos comerciais separadamente. Devido à impreterível consonância de política comercial externa desses Estados, diferentemente da Ásia, onde há proliferação de negociações bilaterais devido à maior autonomia dos países da Associação de Nações do Sudeste Asiático (ASEAN)11 a a UE apresenta majoritariamente acordos plurilaterais e conta com 55 APCs vigentes, excluindo-se aqueles referentes ao seu alargamento.

\footnotetext{
8 Um APC bilateral é o acordo Chile-EFTA (Associação Europeia de Livre Comércio) de 2003.

9 O Mercado Comum do Sul (MERCOSUL) é exemplo de acordo plurilateral.

${ }^{10} \mathrm{O}$ acordo União Aduaneira da África Austral (UAAA) e EFTA (2006) é um exemplo inter-regional.

${ }^{11}$ Composta inicialmente por Indonésia, Malásia, Filipinas, Tailândia e Cingapura.
} 
A classificação quantitativa é aqui ressaltada devido à sua relevância para a compreensão da proliferação dos APCs ao longo das décadas. Contudo, é igualmente importante verificar a emergência de negociações realizadas entre PEDs e PMDs, como acordo Japão-Indonésia (assinado em 2007), ChileTailândia (2013) e Argentina-Brasil (2016).

Além da facilitação da transação de bens e serviços, frente às dificuldades enfrentadas pelo regime multilateral de comércio, a opção pelos APCs é vantajosa ao conferir auxílio aos países menos desenvolvidos e em desenvolvimento na efetivação de reformas econômicas internas que concedam melhores condições para sua abertura comercial, facilitando sua integração no mercado global (CRAWFORD; FIORENTINO, 2005). Devido a isso, identifica-se uma tendência à contínua realização dos APCs promovida, principalmente, pelos países e regiões que ainda mostram-se "defasados" perante os demais.

\section{Proliferação Mundial de APCs: Tendências}

Os APCs não são um fenômeno recente nas relações internacionais, presentes na organização político-econômica dos Estados há séculos. Bhagwatti (1993) e Fawcett (2000), por exemplo, evidenciam que a primeira "onda" de APCs ocorreu entre as décadas de 1950 e 1970, quando, no cenário de Guerra Fria, observou-se um movimento crescente por parte dos países de cooperarem na área de segurança. Neste sentido, formaram-se a Comunidade Econômica Europeia (CEE), em 1957, e a Associação de Nações do Sudeste Asiático (ASEAN), em 1967. Houve, ainda, outras iniciativas de integração entre as nações do Terceiro Mundo contra o alinhamento automático às grandes potências, que levaram à formação da Associação Latino-Americana de Livre Comércio (ALALC) ${ }^{12}$, o Mercado Comum Centro-Americano $(\mathrm{MCCA})^{13}$.

O fim da Guerra Fria, no início da década de 1990, deu início ao ressurgimento de uma nova "onda" de APCs, os quais haviam sido afetados pela crise internacional dos anos 1970, contando com a participação inédita dos EUA, por meio do estabelecimento do Acordo de Livre Comércio da América do Norte (NAFTA) ${ }^{14}$ em 1994 (FAWCETT, 2000). Nesta fase, a própria forma de realização do comércio regional se modificou, passando a considerar novos temas (como defesa comercial, propriedade intelectual e regras de meio-ambiente), abordados pelo regime internacional de comércio multilateral de forma incipiente, e adotando uma regulamentação própria, a qual deu o tom dos novos acordos formalizados (OLIVEIRA, 2013).

A partir de 2001, com a instauração da Rodada Doha, os APCs se proliferaram (DIETER, 2008), dando início a uma terceira "onda" de regionalismo (BAGHAWATI, 1993). A falta de consenso nesta rodada

\footnotetext{
${ }^{12}$ Membros da ALALC: Argentina, Brasil, Bolívia, Chile, Colômbia, Equador, México, Paraguai, Peru, Uruguai e Venezuela.

13 Membros fundadores: Costa Rica, El Savador, Guatemala, Honduras e Nicarágua.

${ }^{14}$ Membros: Estados Unidos, Canadá e México.
} 
fez com que os países buscassem nos APCs alternativas mais rápidas e menos burocráticas para o alcance de seus objetivos comerciais, principalmente em curto prazo.

Por não dependerem de rodadas longas para serem firmados, os APCs se ajustam perfeitamente aos objetivos políticos dos governos democráticos. Suas conclusões supostamente mais rápidas, somadas ao retorno positivo que recebem da mídia, vão à contramão da letargia observada nas negociações da $\mathrm{OMC}$, as quais causam dificuldades aos partidos que almejam a reeleição e não conseguiram apresentar resultados conclusivos na área comercial em seu primeiro mandato (DIETER, 2008).

Acrescido a este cenário político, a pressão exercida por parte das empresas multinacionais reforça a necessidade dos países de fomentarem acordos comerciais mais rápidos e com menos membros à mesa de negociações (DIETER, 2008). As dificuldades encontradas nas rodadas de negociação da OMC, cujo processo decisório é por consenso (com relação às disciplinas, códigos e regras comerciais), impactam os fluxos comerciais de grandes players do comércio internacional onde se localizam empresas de matriz produtiva fragmentada entre PDs e em PEDs e PMDs. Essas empresas transnacionais se valem da queda de barreiras ao comércio, proporcionada pelos APCs, para manter suas exportações e importações, uma vez que optam pela divisão de sua cadeia produtiva entre as diversas nações do globo. Geralmente, a produção de grande escala e intensiva em mão de obra se localiza nos PEDs e PMDs, ao passo que o aparelho burocrático, tecnológico e legal, concentra-se nos países centrais. Apple, GAP e Samsung, são exímios emuladores desta tendência industrial, a qual visa menores custos e, consequentemente, maiores lucros.

O engajamento dos países em APCs ocorre, ainda, devido às facilidades que os Estados adquirem ao acessar mercados estrangeiros, assim que tais acordos são concluídos (CRAWFORD; FIORENTINO, 2005). Em função disso, observa-se que como os membros da OMC não apresentam vontade política necessária à conclusão da liberalização a nível multilateral, os Estados iniciam parcerias comerciais que Ihes viabilizarão alcançar seus objetivos econômicos (tais como a redução de barreiras tarifárias, a implantação de legislação antidumping, a facilidade de acesso a mercados restritos, as vantagens de custo de insumos e de mão de obra), políticos (conforme agenda política comercial dos governantes) e de segurança almejados (CRAWFORD; FIORENTINO, 2005). Neste sentido, os reveses identificados durantes as negociações da OMC, ao se cristalizarem com o início da Rodada Doha, abriram espaço para o caleidoscópio de APCs em todas as regiões do mundo.

Mais do que isso, a opção pelos APCs está intrinsicamente ligada às dificuldades encontrada pelos países em concluírem acordos satisfatórios sobre temas sensíveis nas rodadas multilaterais de negociação comerciais, principalmente no que tange às questões de investimento direto externo, competição, medidas sanitárias e fitossanitárias, e níveis de trabalho (CRAWFORD; FIORENTINO, 2005). Oliveira (2013) evidencia que esses acordos apresentaram regras novas e próprias, as quais podem ser separadas conforme o seu caráter: os acordos que aprofundam as regras multilaterais já existentes são OMC plus, ao passo que os que criam novas regras multilaterais para setores não considerados previamente são OMC extra. Assim, como os APCs oferecem a oportunidade de se estabelecer uma temática ampla e livre de 
restrições, como na OMC, os Estados os utilizam como veículos para liberalização dos seus mercados, o que, novamente, reforça a sua expansão e proliferação.

É contra intuitivo imaginar a existência diversas instâncias de negociações do comércio internacional coexistindo, quando a OMC deveria ter capacidade de exigir determinado nível de comprometimento de seus membros. Ocorre que, paradoxalmente, existem as três, já mencionadas, exceções ao Artigo I do GATT, as quais autorizam a formação de APCs que são discriminatórios por natureza (OLIVEIRA, 2013). Devido a estas cláusulas de escape, atualmente, pode-se observar um spaghetti bowl de APCs (BHAGWATTI, 2002). Esse fenômeno faz menção à multiplicidade de APCs formados ao redor do globo, os quais, em certa medida, formam um emaranhado de teias. Os APCs possuem elevado número de adeptos e são estruturas distintas e complexas.

Essa complexidade na configuração dos APCs, novamente, remete à necessidade de adequação dos padrões de comércio ao novo cenário internacional, o qual tenta suprir o regime multilateral em crise ao promover comércio em nível bilateral, regional e plurilateral. Oliveira (2013) relembra, todavia, que os APCs podem gerar custos, incoerência, imprevisibilidade e instabilidades nas relações internacionais, uma vez que são pouco regulamentados pela $\mathrm{OMC}$, se sobrepõem nas mais diversas temáticas e têm seus próprios mecanismos de solução de controvérsias. Portanto, os APCs, ao mesmo tempo em que conduzem à complexa e ampla interdependência global de seus atores, também resulta em inevitável fragmentação do sistema de regras e normas do comércio internacional (ACHARYA, 2017). Cabe mencionar que os APCs são distintos e têm caráter multifacetado, afinal, se ajustam às necessidades dos players em negociação na medida em que cada parte pode acrescentar à pauta de discussão assuntos de seu interesse e de acordo com o grau de liberalização almejado.

Esse caráter não padronizado dos APCs, por sua vez, gera relações comerciais discriminatórias, as quais privilegiam alguns países em detrimento dos demais. Devido a isto, é possível identificar nações que se beneficiam mais da nova modalidade comercial do que outras, principalmente no que tange às trocas Norte-Sul. Como os mercados do hemisfério norte são especializados na produção de bens tecnológicos e de elevado valor agregado, sua pauta exportadora não equivale à matriz produtiva de países periféricos, os quais exportam, majoritariamente, bens agrícolas e minerais. Esta situação, por sua vez, agrava as desigualdades regionais e perpetua um sistema de contínua rivalidade comercial entre os mercados do Centro e da Periferia.

Ainda assim, é possível identificar que os APCs têm auxiliado na liberação e facilitação do comércio, principalmente em um cenário de letargia das negociações na OMC. São, afinal, esses acordos que vêm oferecendo alternativas à continuação do regime multilateral de comércio, haja vista as dificuldades estruturais e falhas operacionais identificadas na OMC.

\section{CONCLUSÃO}


A despeito de suas limitações, o GATT foi, indubitavelmente, um fórum fundamental para a liberalização do comércio multilateral do pós-Segunda Guerra até o início de 1990. No arcabouço dos regimes internacionais, a OMC teve sucesso em implementar acordos para abertura de mercados, regular o comércio e agregar membros, além de que institucionalizou o OSC. Fundada no contexto do pós-Guerra Fria, os EUA tiveram um papel diferente na conformação da OMC em relação ao GATT, assinado no pósSegunda Guerra quando o país tinha poder para moldar as instituições e os regimes econômicos internacionais. Após o lançamento da Rodada Doha, ficou evidente a crise da OMC dadas suas dificuldades em concluir acordos sobre questões sensíveis, avançar na elaboração de disciplinas comerciais e equilibrar muitos interesses. Por conta disso, os APCs se proliferaram em todas as regiões do mundo.

Os APCs, todavia, não resultam apenas da perceptível demora na conclusão das reuniões ministeriais da OMC. Observa-se o estabelecimento, por parte dos Estados-membros, de barreiras nãotarifárias ao comércio e de pautas comerciais que tangenciam os acordos tipo OMC plus e extra. Tem-se, ainda, que a falta de vontade política dos grandes players do comércio internacional abriu espaço para perpetuação de uma visão menos liberal, a qual opta pela conclusão de APCs, os quais são supostamente mais rápidos e menos burocráticos. Mais do que isso, compreende-se que o crescente embate político dentro da OMC, com disputas sobre as agendas de negociação entre PDs e PEDs, também contribui para a busca de mecanismos de cooperação de escopos reduzidos e focalizados nos interesses das partes em questão.

Assim, os APCs decorrem da crise do regime multilateral de comércio e são consequência de alterações nos objetivos econômicos, políticos e de segurança dos PDs e PEDs, os quais passaram a eleger instrumentos que apresentassem resultados (supostamente) imediatos. Iniciando no começo deste século, a proliferação dos APCs apresenta tendências à perpetuação, haja vista resultados empíricos evidenciados e a compreensão de que os estrangulamentos enfrentados pela OMC seguirão como um empecilho à manutenção do comércio multilateral.

* Artigo recebido em 03 dez 2017, aprovado em 19 abr 2018.

\section{REFERÊNCIAS}

ACHARYA, Amitav. Global Governance in a Multiplex World. EUI Working Paper RSCAS, n. 29, 2017.

ACHARYA, Amitav. et al. Landscape. In: CHAUFFOUR, Jean-Pierre.; MAUR, Jean-Maur. (eds.).

Preferential Trade Agreement Policies for Development: a Handbook. World Bank Group. Washington, 2011. 
BACCINI, Leonardo. DÜR, Andreas. ELSIG, Manfred. The Design of International Trade Agreements: Introducing a New Database. Review of International Organizations, 2014.

BHAGWATI, Jagdish. Regionalism and Multilateralism: an Overview. In: DE MELO, J.; PANAGARIYA, Arvind(ed.). A. New Dimensions in Regional Integration. Cambridge: Cambridge University Press, 1993.

BHAGWATI, Jagdish. Free trade today. Princeton: Princeton University Press, 2002.

BHAGWATI, Jagdish; KRISHNA, Pravin; PANAGARIYA, Arvind. The World Trading System. Geoeconomics Strategy Conference, May, 2014.

CRAWFORD, Jo-Ann. FIORENTINO, Roberto. The Changing Landscape of Regional Trade Agreements. WTO Publications Discussion Papers. n. 8, Geneve, 2005.

DEBLOCK, Christian. HAMER, Bruno. Bretton Woods et l'ordre économique internationale d'aprèsguerre. Interventions Economiques, n. 26, p.9-42, 1994.

DIETER, Heribert. The Multilateral Trading System and Preferential Trade Agreements: can their negative effects be minimized? GARNET Working Paper, No: 54/08, University of Warwick, 2008.

FAWCETT, Louise. Regionalism in Historical Perspective. In: FAWCETT, L. HURRELL, A. (eds.). Regionalism in World Politics, 2000.

GILPIN, Robert. Global Political Economy: understanding the International Economic Order. Princeton: Princeton University Press, 2001.

HASENCLEVER, Andreas; MAYER, Peter; RITTBERGER, Volker. Theories of International Regimes. Cambridge: Cambridge University Press, 2000.

HUDEC, Robert. Developing Countries in the GATT Legal System. Editora Gower. Trade Policy Research Center, London, 1987.

JACKSON, John. The World Trading System: Law and Policy of International Economic Relations. $2^{\text {a Ed. }}$ Cambridge: The MIT Press, 1997.

KEOHANE, Robert. O. Multilateralism: an Agenda for Research. International Journal, vol.45, p.731-764, 1990.

KEOHANE, Robert. International Institutions and State Power. Boulder, Co.: Westview Press, 1989.

MESQUITA, Paulo. A Organização Mundial do Comércio. FUNAG, Brasília, 2013.

O'BRIAN, Robert; WILLIAMS, Marc. Global Political Economy: Evolution and Dynamics. New York: Palgrave Macmillian. 2a ed., 2004. 
OLIVEIRA, Ivan. Os Acordos Preferencias e a Regulação do Comércio Global no Século XXI. In: OLIVEIRA, Ivan; BADIN, Michelle. (eds.). Tendências Regulatórias nos Acordos Preferenciais de Comércio no Século XXI: os casos de Estados Unidos, UE, China e Índia. IPEA. Brasília, 2013.

PANAGARIYA, Arvind. The Regionalism Debate: An Overview. The World Economy. vol. 22, n. 4, p. 455476, 1999.

PRAZERES, Tatiana. Comércio Internacional e Protecionismo: as barreiras técnicas na OMC. Ed. Aduaneiras, 2002.

RUGGIE, John. International Regimes, Transactions, and Change: Embedded Liberalism in the Postwar Economic Order. International Organization, vol. 36, n. 2, International Regimes, p. 379-415, 1982.

SATO, Eiiti. Economia e política das relações internacionais. Fino Traço Editora, 2012.

SATO, Eiiti. Mudanças estruturais no sistema internacional: a evolução do regime de comércio do fracasso da OIC à OMC. UFGRS, 2001.

THORSTENSEN, Vera. A OMC - Organização Mundial do Comércio e as negociações sobre investimentos e concorrência. Revista Brasileira Politica Internacional. vol. 41, n.1, p. 57-89, 1998.

THORSTENSEN, Vera. Impactos da Crise Econômica e Financeira na Regulação do Comércio Internacional. Boletim de Economia e Política Internacional. IPEA, Brasília, 2012.

VANGRASSTEK, Craig. The History and Future of the World Trade Organization. World Trade Organization. Geneva, 2013.

WILLIAMS, Gwyneth. The First United Nations Conference on Trade and Development Geneva, 1964. In: WILLIAMS, Gwyneth (ed.). Third-World Political Organizations, 1987.

WOOLCOCK, Stephen. The Evolution of the International Trading System. In HEYDON, Kenneth; WOOLCOCK, Stephen. (eds.). The Ashgate Research Companion. London: Ashgate. 2012. 